\title{
Bone Defect Reconstruction in a 2 Years Old Boy with Non-Vascularized Fibular Graft Using the Induced Membrane Technique in Country with Low-Income: A Case Report
}

\author{
Kombate Noufanangue Kanfitine ${ }^{1 *}$, Ayouba Gamal2, Bakriga Batarabadja ${ }^{2}$, \\ Walla Atchi ${ }^{3}$, Abalo Anani Grégoire ${ }^{2}$
}

${ }^{1}$ Department of Orthopaedic and Traumatology Surgery, Saint-Jean de Dieu d'Afagnan Hospital, Lomé, Togo

${ }^{2}$ Department of Orthopaedic and Traumatology Surgery, Teaching University Hospital Sylvanus Olympio, Lomé, Togo

${ }^{3}$ Department of Orthopaedic and Traumatology Surgery, Campus Teaching University Hospital, Lomé, Togo

Email: *kludovick67@yahoo.fr

How to cite this paper: Kanfitine, K.N., Gamal, A., Batarabadja, B., Atchi, W. and Grégoire, A.A. (2018) Bone Defect Reconstruction in a 2-Year-Old Boy with Non-Vascularized Fibular Graft Using the Induced Membrane Technique in Country with Low-Income: A Case Report. Open Journal of Orthopedics, 8, 458-463.

https://doi.org/10.4236/ojo.2018.812047

Received: October 5, 2018

Accepted: December 10, 2018

Published: December 13, 2018

Copyright () 2018 by authors and Scientific Research Publishing Inc. This work is licensed under the Creative Commons Attribution International License (CC BY 4.0).

http://creativecommons.org/licenses/by/4.0/

\begin{abstract}
Chronic osteomyelitis in children is frequent in the developing countries. Their complications and morbidity burden the functional prognosis. The reconstruction of diaphyseal bone loss after sequestrectomy in young children remains a difficult and expensive challenge in our context. The delay in care and the lack of social security for all, are risk factors for morbidity. The induced membrane technique described by Masquelet starts to be applied and showed satisfactory results. We report the results of a case of reconstruction of the proximal humerus by using a non-vascularized fibula and supplemental bone substitute in a boy of 2 years with sickle cell. No scarring occurred at the sampling site. The process of bone consolidation is underway.
\end{abstract}

\section{Keywords}

Chronic Osteomyelitis, Bone Defect, Bony Bone Reconstruction, Induced Membrane, Fibula

\section{Introduction}

Chronic osteomyelitis in children is frequent in the developing countries [1].

The etiologies are varied; their complications and morbidity compromised the functional prognosis. Reconstruction of bone loss after sequestration, using non-vascularized fibula graft remains a challenging problem to treat. This technique was used by several authors in surgery of diverse reconstruction [2] [3] 
[4].

The use of the induced membrane technique described by Masquelet [5] allows the reconstruction in two steps of the losses of bone substances with good results.

During the first step, a spacer was inserted after sequestrectomy. The cement spacer was removed during the second step procedure after antibiotherapy and fibular graft. We report a preliminary result in 2-year-old boy of a case of reconstruction of proximal humerus by using a non-vascularized fibula with additional bone substitute.

\section{Case Report}

A 2 years old boy, right-handed with sickle cell anemia heterozygous S/C, presenting a chronic osteomyelitis of proximal humerus was treated during 6 months by a traditional procedure.

At the time when he was addressed to us in March 2017, the physical examination found neither vascular nor nerve disorder. The pain was $8 / 10$ on an analogical visual scale. The passive mobility amplitudes of the elbow were: flexion 80 degrees, extension 15 degrees, pronation 45 degrees and supination 40 degrees; the abduction was limited to 45 degrees. The mobility of the right shoulder was painful with an epiphysiolysis of the ossification nucleus on Radiography. An active fistulous orifice was located on the antero-external face of the proximal third of the right humerus. The radiographic evaluation showed a sequestrum of $6 / 1$ centimeters in diameter without periosteal reaction on the proximal third of the humeral shaft. The cytobacteriological examination had isolated the staphylococcus aureus.

The reconstruction was initially begun by removing the bone sequestrator and placing a gentamycin spacer. The right upper limb was immobilized by a thoraco-brachial plaster for 6 weeks. A suitable parenteral antibiotherapy was managed during 8 weeks.

The child was lost to sight for 3 months in the follow-up of the first step and came back with a continuity solution between bone and spacer (Figure 1).

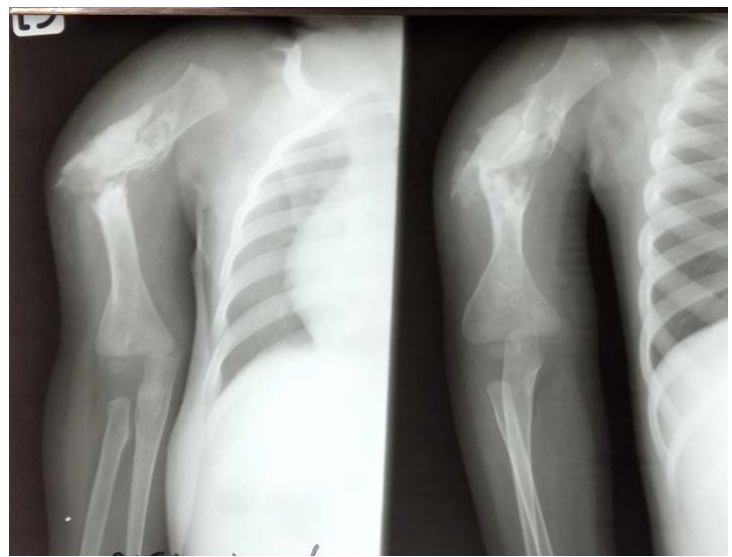

Figure 1. Solution of continuity sitting at the interface bone-spacer. 
The second stage consisted of the explantation of the spacer (Figure 3) and the put on a non-vascularized fibula of $8 \mathrm{~cm}$, taken from the homolateral leg by open procedure.

The surgical specimen was taken from patient on dorsal supine with a cushion under the buttock and under the pneumatic tourniquet. The intended osteotomy site was 6 centimeters from the fibula (Figure 2).

The transplant was introduced into the medullary canal of the Proximal and distal segment of the right humerus (Figure 3).

Stabilization was performed by elastic nail, using retrograde approach, on the lateral epicondyle, without fluoroscopic views. A supplement of $20 \mathrm{ml}$ of granulated bone substitute was required (Figure 4). Additional immobilization by thoraco-brachial plaster was necessary.

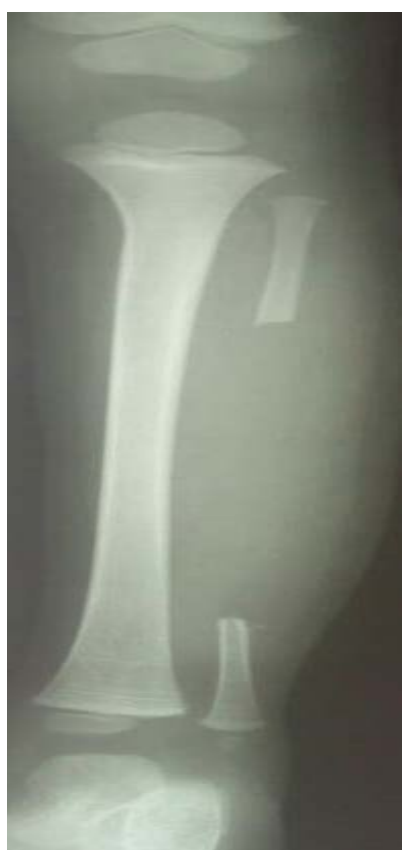

Figure 2. Site of osteotomy of fibula.

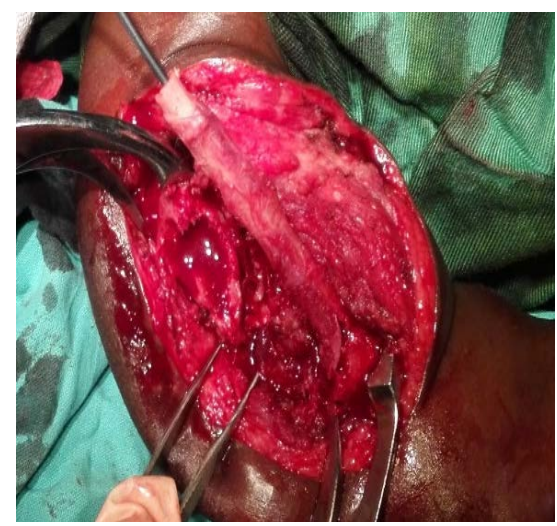

(a)

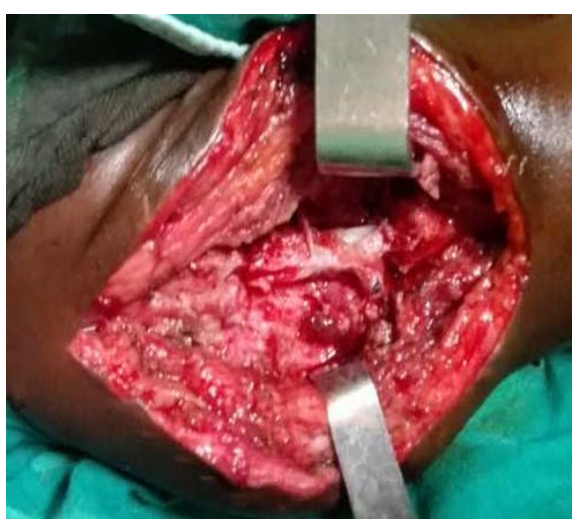

(b)

Figure 3. (a) Introduction of the fibular transplant into the segment distal of the humerus; (b) Stabilization of the hearth using elastic nail. 
The operative sequences were simple locally; there was no scarring incident at the site of the sampling.

The child was reviewed two months later. Bone consolidation is underway. There is a residual lameness.

Bone consolidation was achieved with a fistula orifice 6 months later. However, bone substitute integration is underway (Figure 4). The clinical results were satisfactory with good mobility of elbow and shoulder (Figure 5).

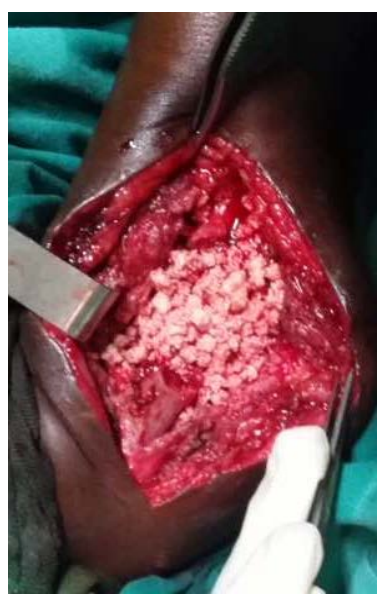

(a)

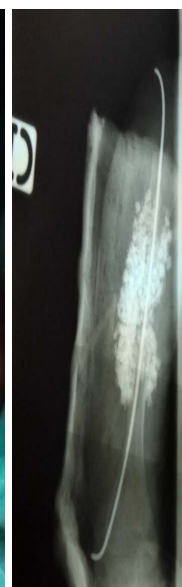

(b)

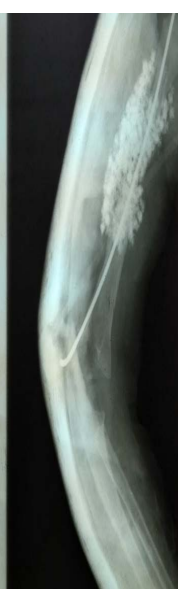

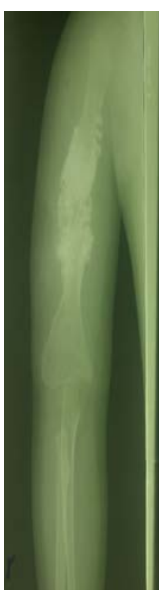

(c)

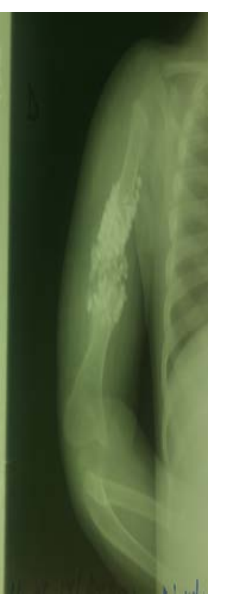

Figure 4. (a) Massive supplemental bone substitute after stabilization; (b) Postoperative result; (c) Radiographs taken 6 months after elastic nail removal.

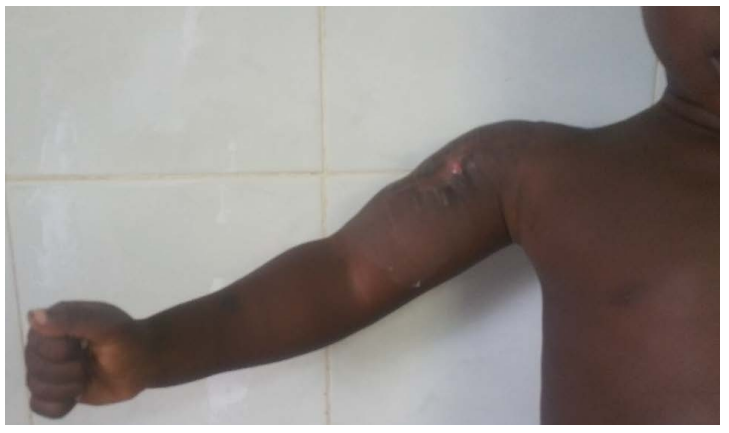

(a)

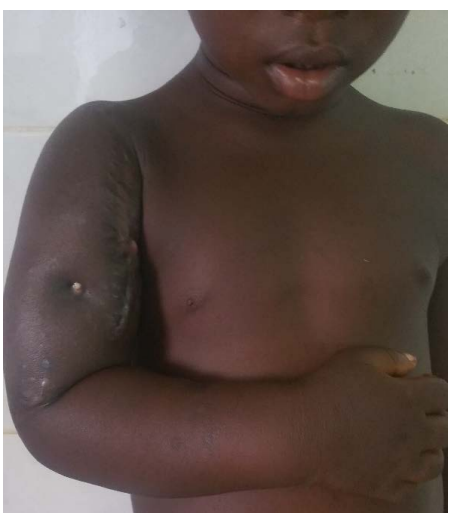

(b)

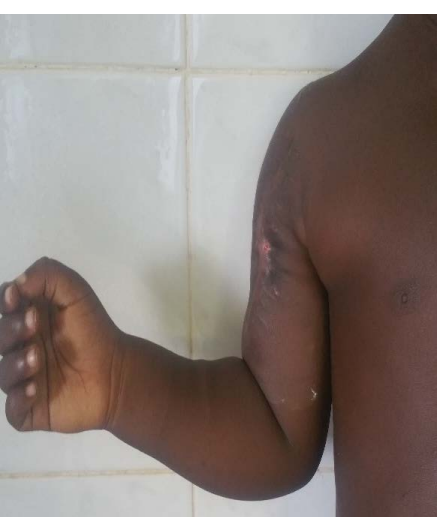

(c)

Figure 5. Functional results (a) Abduction; (b) Internal rotation; (c) External rotation. 


\section{Discussion}

The treatment of the loss of bone substances of the humerus in septic medium in the young child is a difficult and expensive challenge in our context. The delay of care and lack of social security for all are risk factors for morbidity and significant functional sequelae. Chronic osteomyelitis of humeral shaft is rare. This pathology was caused by an infecting microorganism; hematogenous staphylococcus aureus is by far the most commonly involved. The reconstruction of defect secondary to chronic osteomyelitis remains a challenging problem [4]. The free vascularized fibular graft used for the great reconstruction of bone was approved by some authors [6] [7]. But non-vascularized fibular graft used only, were considered such as an inappropriate filling up bone defect [8]. We used the induced membrane technique combined (non-vascularized fibula graft with massive bone allograft) for the treatment of bone defects resulting from sequestrectomy of chronic osteomyelitis in 2-year-old boy.

A scarring incident of the donor site was found. On the other hand, no resurgence infection was observed in our study. In the literature, complications related to the scar after removal and paralysis of the spontaneously resolving fibular nerve have been reported [9] [10]. This postoperative weakness of the long involved fibular is a consequence of the disintegration of the muscular origins after the partial fibulectomy [11]; this could explain the discreet lameness found in our case (Figure 2).

In the princeps technique of Masquelet et al. [12], the addition of a cortical graft is not recommended, the autograft is made parcelled out grafts. In our case, the reconstruction of the defect of the proximal of the humerus after sequestrectomy required $8 \mathrm{~cm}$ length free fibular graft with contribution complementary to $20 \mathrm{ml}$ of bone substitute. The procedure of consolidation is going on. Proximal humeral epiphysiodesis is due to prolonged immobilization and to the reorganization of the physis by the infectious process. The prolonged immobilization was reported by Daoud et al. [13]. Our clinical results were satisfactory outside the fistulous orifice (Figure 5). Pho et al. [14] reported good mobility results in terms of abduction and antepulsion respectively of $80^{\circ}$ and $70^{\circ}$.

\section{Conclusion}

The use of a non-vascularized fibular graft combined with the induced membrane technique is an alternative for the reconstruction of major bone loss in children. It allows to preserve the length of the limb and the articular mobility. The management is simple and does not require a particular specialized training.

\section{Conflicts of Interest}

The authors declare that they have no competing interests.

\section{References}

[1] Maissavou, A., Mbambe King, M., Bolde, I. and Diane, C. (1995) La place de la 
séquestrectomie osseuse dans les ostéomyélites chronique de l'enfant: expérience de 10 ans à l'hôpital pédiatrique d'Ouvendo de Libreville. Medecine d'Afrique Noire, 10, 494-497.

[2] Krieg, A.H. and Hefti, F. (2007) Reconstruction with Non-Vascularised Fibular Grafts after Resection of Bone Tumours. The Journal of Bone and Joint Surgery British, 89, 215-221. https://doi.org/10.1302/0301-620X.89B2.17686

[3] Steinlechner, C.W. and Mkandawire, N.C. (2005) Non-Vascularised Fibular Transfer in the Management of Defects of Long Bones after Sequestrectomy in Children. The Journal of Bone and Joint Surgery British, 87, 1259-1263. https://doi.org/10.1302/0301-620X.87B9.15734

[4] Patwardham, P.K., Mehta, R. and Agrawat, H. (2013) Reconstruction of Bones Defects after Osteomyelitis with Non-Vascularised Fibular Graft: A Retrospective Study in Twenty-Six Children. The Journal of Bone \& Joint Surgery, 95, e56. https://doi.org/10.2106/JBJS.K.01338

[5] Masquelet, A.C. and Begue, T. (2010) The Concept of Induced Membrane for Reconstruction of Long Bone Defects. Orthopedic Clinics of North America, 41, 27-37. https://doi.org/10.1016/j.ocl.2009.07.011

[6] Jaguer, T., Journeauu, P., Dautel, G., Barbary, S., Haumont, T. and Lascombes, P. (2010) Is Combining Massive Bone Allograft with Free Vascularized Fibular Flap the Children's Reconstruction Answer to lower Limb Defect Following Bone Tumor Resection. Orthopaedics \& Traumatology. Surgery \& Research, 96, 340-347. https://doi.org/10.1016/j.otsr.2010.02.003

[7] Wang, X., Luo, F., Huang, K. and Xie, Z. (2016) Induced Membrane Technique for Treatment of Bone Defect Due to Post Traumatic Osteomyelitis. Bone \& Joint Research, 5, 101-105. https://doi.org/10.1302/2046-3758.53.2000487

[8] Steiger, C.N., Journeau, P. and Lascombes, P. (2017) The Role of Periosteal Sleeve in the Reconstruction of Bone Defectusing a Non-Vascularized Fibula Graft in the Paediatric Population. https://doi.org/10.1016/j.otsr.2017.05.027

[9] Shingade, V.U., Jagtap, S.M. and Ranade, A.B. (2004) Weakness of Extensor Hallucis Longus after Removal of Non-Vascularised Fibula as an Autograft. The Journal of Bone and Joint Surgery British, 86, 384-387. https://doi.org/10.1302/0301-620X.86B3.14748

[10] Besarir, K., Selek, H., Yildiz, Y. and Saglik, Y. (2005) Nonvascularised Fibular Grafts in the Reconstruction of Bone Defects in Orthopaedic Oncology. Acta Orthopaedica et Traumatologica Turcica, 39, 300-306.

[11] Gore, D.R., Gardner, G.M., Sepic, S.B., Mollinger, L.A. and Murray, M.P. (1987) Function Following Partial Fibulectomy. Clinical Orthopaedics and Related Research, 220, 206-210. https://doi.org/10.1097/00003086-198707000-00028

[12] Masquelet, A.C., Fitoussi, F., Begue, T. and Muller, G.P. (2000) Reconstruction of the Long Bones by the Induced Membrane and Spongy Autograft. Annales de Chirurgie Plastique Esthétique, 45, 346-353.

[13] Daoud, A. and Saighi-Bouaouima, A. (1989) Treatment of Sequestra, Pseudarthrosis and Defects in the Bones of Children Who Have Chronic Hematogenous Osteomyelitis. The Journal of Bone \& Joint Surgery, 71, 1448-1468. https://doi.org/10.2106/00004623-198971100-00003

[14] Pho, R.W., Patterson, M.H., Kour, A.K. and Kumar, V.P. (1998) Free Vascularised Épiphyseal Transplantation in Upper Extremity Reconstruction. The Journal of Hand Surgery: British \& European Volume, 13, 440-447. https://doi.org/10.1016/0266-7681(88)90175-1 